\title{
Los exámenes preliminares de la Corte Penal Internacional en América Latina: el caso colombiano y su impacto sobre futuras negociaciones de paz en la región
}

\section{Preliminary examinations of the International Criminal Court in Latin America: the Colombian case and its impact on future peace negotiations in the region}

\author{
Héctor Olásolo Alonso \\ Instituto Iberoamericano de la Haya para la Paz, los Derechos Humanos y la Justicia Internacional (IIH)
}

Es Magíster en Derecho por Universidad de Columbia (Nueva York) y Licenciado, Doctor y premio extraordinario de doctorado por la Universidad de Salamanca (España). En la actualidad se desempeña como profesor titular de carrera de la Facultad de Jurisprudencia de la Universidad del Rosario (Bogotá, Colombia), es presidente del Instituto Iberoamericano de la Haya para la Paz, los Derechos Humanos y la Justicia Internacional (IIH) y director del Anuario Iberoamericano de derecho Internacional Penal (ANIDIP). En el pasado se ha desempeñado como profesor titular de Derecho Penal y Procesal Internacional de la Universidad de Utrecht (Holanda); letrado de Sala de la Corte Penal Internacional (2004-2010); miembro de la asesoría jurídica y de la sección de apelaciones del Tribunal Penal Internacional para la ex Yugoslavia (2002-2004) y; miembro de la delegación española en la Comisión Preparatoria para la Corte Penal Internacional celebrada en la sede de la Organización de las Naciones Unidas en Nueva York (1999-2002). Ha escrito 15 monografías y más de sesenta artículos y capítulos de libros en publicaciones jurídicas de reconocido prestigio. hectorolasolo@gmail.com

\section{RESUMEN}

El artículo comienza analizando la función de la Fiscalía de la Corte Penal Internacional en la aplicación del principio de complementariedad, a través de los exámenes preliminares realizados durante los diez primeros años de funcionamiento de la Corte Penal Internacional. Se subraya la relevancia de los exámenes preliminares para fortalecer los órganos jurisdiccionales nacionales y el Estado de Derecho en los Estados afectados, y se constata que cada situación bajo examen requiere de una estrategia de actuación diferente debido a las particulares circunstancias que la rodean. A continuación, se analizan las características del fenómeno de la lesa humanidad en Colombia y las consecuencias de su configuración como crímenes internacionales de ius cogens. A la luz de lo anterior, se aborda el impacto del examen preliminar que la Fiscalía de la CPI viene desarrollando sobre la situación de Colombia para las actuales negociaciones de paz entre el Gobierno y las FARC. Para finalizar, el autor realiza algunas observaciones finales sobre la importancia de este examen preliminar más allá de Colombia para futuras negociaciones de paz en la región.

Palabras clave: Corte Penal Internacional- crímenes de lesa humanidad- principio de complementariedad exámenes preliminares- justicia transicional Colombia.

\section{ABSTRACT}

The article initially traces back the International Criminal Court Prosecutor's role in the application of the complementarity principle in preliminary examinations during the first ten years of the International Criminal Court. The article emphasises the role played by preliminary examinations in strengthening countries national jurisdictions and the rule of law, verifying that each case requires a different strategy due to its particular circumstances. Crimes against humanity characteristics in Colombia are subsequently analysed and the consequences of its configuration as a jus cogens international crimes. Based on the aforementioned, it discusses the impact of preliminary examinations on the current peace negotiations between the Colombian Government and the FARC developed by the International Criminal Court Prosecutor. In conclusion, the article gives some final observations about the importance of preliminary examinations for future peace negotiations in the region beyond the Colombian case.

Key words: International Criminal Court - crimes against humanity - complementarity principle preliminary examination - Colombia transitional justice. 


\section{Introducción}

Desde su creación, la Fiscalía de la Corte Penal Internacional (CPI) ha utilizado los exámenes preliminares previos a la apertura formal de una investigación, para llamar la atención de la comunidad internacional sobre los crímenes cometidos y la impunidad de sus presuntos autores ${ }^{1}$. Para ello, como lo muestran las situaciones en Colombia ${ }^{2}, \mathrm{Kenia}^{3}$, Georgia ${ }^{4}$ y Guinea ${ }^{5}$, además de recibir testimonios y buscar información de diversas fuentes ${ }^{6}$, la Fiscalía ha recurrido con frecuencia a canales diplomáticos y medios de comunicación ${ }^{7}$.

Asimismo, la Fiscalía de la CPI ha subrayado durante sus exámenes preliminares que las autoridades nacionales de los Estados afectados pueden cumplir con sus obligaciones y evitar la apertura de una investigación, siempre y cuando tomen las medidas necesarias para que sus jurisdicciones nacionales procedan a una genuina persecución penal de los delitos de genocidio,

1 OLÁSOLO, Héctor. "El principio de complementariedad y las estrategias de actuación de la Corte Penal Internacional en la fase de su examen preliminar. ¿Por qué la Corte Penal Internacional mantiene su examen preliminar, pero no abre una investigación sobre la situación en Colombia?". Revista electrónica de estudios internacionales, Vol. 24, No.2, 2012, pp.1-45. Disponible [en línea] <http://www.reei.org/index.php/revista/num24/articulos/principio-complementariedad-estrategias-actuacion-corte-penal-internacional-fase-examen-preliminar-corte-penal-internacional-mantiene-su-examenpreliminar-pero-abre-una-investigacion-sobre-situacion-colombia> [consulta: 31 de enero de 2014].

2 Véase, Fiscalía de la CPI. Report on the Preliminary Examination Activities, diciembre de 2011, párr.85. Disponible [en línea] <http://www.icc-cpi.int/en_menus/icc/structure\%20of\%20the\%20court/office $\% 20$ of $\% 20$ the\%20 prosecutor/comm\%20and\%20ref/Pages/otp\%20report\%20on\%20preliminary\%20examinations_\%2013\%20december\%202011.aspx> [consulta: 31 de enero de 2014]. Véase también Fiscalía de la CPI. Report on Preliminary Examination Activities, noviembre de 2012, pp. 11-15. Disponible [en línea] <http://www.icc-cpi.int/NR/rdonlyres/ C433C462-7C4E-4358-8A728D99FD00E8CD/285209/OTP2012ReportonPreliminaryExaminations22Nov2012. pdf> [consulta: 31 de enero de 2014].

3 Véase OLÁSOLO, Héctor y CARNERO, Enrique. "Aplicación práctica del análisis de admisibilidad de situaciones: la situación en la república de Kenia". En: OLÁSOLO, Héctor. Ensayos de Derecho Penal y Procesal Internacional. Valencia: Tirant lo Blanch e Instituto Iberoamericano de la Haya (IIH), 2011, pp. 105-108.

$4 \quad$ En relación con el examen preliminar de la situación en Georgia, desde que el Fiscal de la CPI lo hizo público el 14 de agosto de 2008: (i) el Ministro de Justicia de Georgia ha visitado al Fiscal de la CPI en la Haya; (ii) 3817 comunicaciones individuales han sido enviadas al Fiscal de la CPI desde la Federación Rusa (un Estado no parte); (iii) el Fiscal ha solicitado información a los gobiernos de la Federación Rusa y de Georgia el 27 de agosto de 2008, y ambos han respondido; (iv) dos visitas a Georgia han sido realizadas por personal de la Fiscalía de la CPI en noviembre de 2008 y en junio de 2010; y (v) dos visitas a Rusia han sido realizadas por personal de la Fiscalía de la CPI en marzo de 2010 y en febrero de 2011 para analizar el desarrollo de los trabajos del Comité de Investigación de la Federación Rusa.

En relación con el examen preliminar de la situación en Guinea, desde que el Fiscal de la CPI lo hizo público el 14 de octubre de 2009: (i) el Fiscal de la CPI ha sostenido en enero de 2010 consultas con el Presidente de Burkina Faso (mediador del grupo de contacto para Guinea) y con el presidente de Senegal, a los efectos de asegurarse que ambos eran adecuadamente informados sobre el trabajo del Fiscal; (ii) hasta seis visitas del personal de la Fiscalía a Guinea han tenido lugar entre 2010 y 2012, la última encabezada por la actual Fiscal Jefe de la CPI, Fatou Bensouda (en aquel entonces Fiscal Jefe Adjunta) del 4 al 6 de abril de 2012. Durante estas visitas se han entrevistados con numerosas autoridades nacionales y organizaciones de la sociedad civil (incluyendo entre otros al Presidente de Guinea, a su Ministro de Justicia y varios magistrados encargados de las actuaciones nacionales en relación con la masacre cometida el 28 de septiembre de 2012 en el Estadio de Conakry).

6 Artículo 15 (2) Estatuto de Roma (ER), y reglas 104 y 105 de las Reglas de Procedimiento y Prueba de la Corte Penal Internacional.

Información sobre el desarrollo de los exámenes preliminares relativos a cada una de las 18 situaciones que han sido objeto del mismo y sobre los que no se ha tomado la decisión de abrir una investigación, se pueden encontrar en la página oficial de la CPI: [en línea] <http://www.icc-cpi.int/en_menus/icc/structure\%20of\%20the\%20court/ office $\% 20$ of $\% 20$ the $\% 20$ prosecutor/comm $\% 20$ and\%20ref/Pages/communications $\% 20$ and\%20referrals.aspx> [consulta: 31 de enero de 2014]. 
lesa humanidad y crímenes de guerra cometidos en su territorio o por sus nacionales ${ }^{8}$.

De esta manera, los exámenes preliminares se han constituido en una herramienta básica para cumplir con el mandato preventivo de la CPI, mediante la potenciación del Estado de Derecho a nivel nacional ${ }^{9}$ y la dotación de los elementos necesarios para que las jurisdicciones nacionales puedan Ilevar a cabo -de manera independiente e imparcial y dentro de un plazo razonable- la persecución penal de los delitos de la competencia de la $\mathrm{CPI}^{10}$.

El presente trabajo se centra, en primer lugar, en el análisis de los exámenes preliminares realizados por la Fiscalía de la CPI en relación con situaciones en América Latina, con el objeto de mostrar cómo su trabajo es mucho más cercano a la región que lo que se percibe comúnmente. Este análisis nos permitirá además, una mejor comprensión del objeto y función de los exámenes preliminares en el sistema de la CPI.

Sobre esta base, pasaremos a determinar cuál es el impacto del examen preliminar en Colombia respecto a las actuales negociaciones de paz entre el gobierno colombiano y las Fuerzas Armadas Revolucionarias de Colombia (FARC), celebradas en el marco de un conflicto caracterizado por una dinámica de violencia sistemática y generalizada contra la población civil (comprendido éste como un fenómeno de la lesa humanidad). El estudio de esta cuestión es particularmente relevante, si tenemos en cuenta que la Fiscalía de la CPI publicó su segundo informe sobre el examen preliminar en Colombia tres semanas después del inicio oficial de las negociaciones en octubre de 2012, y días antes de que estas se retomaran en La Habana a mediados de noviembre del mismo año.

8 Fiscalía de la CPI. Policy Paper on Preliminary Examinations, noviembre 2013, pp. 12-14. Disponible [en línea] <http://www.icc-cpi.int/en_menus/icc/press\%20and\%20media/press\%20releases/Documents/OTP\%20Preliminary\%20Examinations/OTP\%20-\%20Policy\%20Paper\%20Preliminary\%20Examinations\%20\%202013.pdf> [consulta: 5 de marzo de 2014]. Véase también en este sentido, BURKE-WHITE, William. "Implementing a Policy of Positive Complementarity in the Rome System of Justice". Criminal Law Forum, Vol. 19, 2008, pp. 59 y ss, p. 61 y; HALL, Christopher Keith. "Developing and Implementing an Effective Positive Complementarity Prosecution Strategy" En: STAHN, Carsten y SLUITER, Göran. The emerging practice of the International Criminal Court. Leiden: Brill, 2009, pp. 220 y ss.

9 OLÁSOLO, Héctor. "La función de la Corte Penal Internacional en la prevención de delitos atroces mediante su intervención oportuna: de la doctrina de la intervención humanitaria y de las instituciones judiciales ex post-facto al concepto de responsabilidad de proteger y la intervención oportuna de la Corte Penal Internacional". En: OLÁSOLO, Héctor. Ensayos de Derecho Penal y Procesal Internacional ... op.cit, pp. 45-48.

Fiscalía de la CPI. Borrador de Políticas sobre Exámenes Preliminares, 4 de octubre de 2010, párr. 83. En este contexto, se denomina "complementariedad positiva" a las actividades de asistencia a las autoridades nacionales para que puedan cumplir con su deber de investigar y enjuiciar los delitos ya cometidos. Véase a este respecto, BURKE-WHITE, William. Implementing a Policy... op. cit., p. 61; y HALL, Christopher Keith. Developing and Implementing... op. cit., pp. 220 y ss. Véase también, CROSS, Mattew y WILLIAMS, Sarah. "Recent Developments at the ICC: Prosecutor vs Germain Katanga and Mathieu Ngudjolo Chui: A Boost for Co-operative Complementarity?" Human Rights Law Review, Vol. 10, 2010, pp. 336 y ss, p. 339. Por su parte, el término "complementariedad cooperativa" es utilizado para denominar el reparto de la carga de investigación y enjuiciamiento entre las jurisdicciones nacionales y la CPI, sobre todo cuando existen problemas serios de falta de capacidad. Véase a este respecto, CASSESE, Antonio. "The Rome Statute: A Tentative Assessment". En: CASSESE, Antonio (et al.). The Rome Statute of the International Criminal Court: A Commentary. Oxford: Oxford University Press, 2002, p.1901 y ss, p. 1906; KRESS, Claus. "Self-Referrals' and 'Waivers of Complementarity': Some Considerations in Law and Policy". Journal of International Criminal Justice, Vol. 2, 2004, pp. 944 y ss, pp. 947-948 y; GIOIA, Federica. "State Sovereignty, Jurisdiction, and 'Modern' International Law: The Principle of Complementarity in the International Criminal Court". Leiden Journal of International Law, Vol. 19, 2006, pp. 1095 y ss, p. 1115. Tanto la complementariedad positiva como la complementariedad cooperativa parecen haber sido, en gran medida, implícitamente confirmadas por la decisión de la Sala de Apelaciones de 22 de junio de 2009 en el caso Katanga y Ngudjolo. Véase CPI. Prosecutor vs Germain Katanga and Mathieu Ngudjolo Chui, Decision of the Presiding Judge of the Appeals Chamber in the appeal of Germain Katanga against the Decision of Trial Chamber II of 12 June 2009 on the Admissibility of the Case, Appeals Chamber, caso No. ICC-01/04-01/07-1286, de 10 de julio de 2009. 
Abordaremos en este contexto las conclusiones alcanzadas por las Fiscalía de la CPI sobre la comisión de delitos de lesa humanidad por los distintos actores armados en el conflicto colombiano. A continuación, analizaremos los efectos de la actual configuración en el derecho internacional de los delitos de lesa humanidad como crímenes internacionales de ius cogens, y la consiguiente aceptación del principio "no hay paz sin justicia" en relación con sus máximos responsables. Finalmente, estudiaremos el impacto que el examen preliminar de la Fiscalía de la CPI tiene sobre el proceso de negociación de paz entre el gobierno colombiano y las FARC.

Como explicaremos en las conclusiones a este trabajo, este impacto no solo es extrapolable al desarrollo de futuros procesos de paz en América Latina, sino que brinda parámetros para evaluar procesos de negociación ocurridos en la región desde la creación de la CPI, como el llevado a cabo en Honduras tras el golpe de Estado contra el ex presidente Manuel Zelaya a finales de junio de 2009. Todos estos elementos permitirán ilustrar la importancia de los exámenes preliminares que realiza la CPI y sus importantes repercusiones en América Latina.

\section{Los exámenes preliminares de la Fiscalía de la CPI sobre situaciones en América Latina}

Desde los países de América Latina se tiende a ver la actividad de la CPI como lejana y centrada primordialmente en investigaciones sobre situaciones en África (sobre todo en la región de los grandes lagos). Sin embargo, si bien es cierto que las investigaciones formalmente abiertas por la Fiscalía de la CPI se refieren a las situaciones en Costa de Marfil, Guinea, Kenia, Libia, Mali, República Centroafricana, República Democrática del Congo, Sudán (Darfur) y Uganda, la verdad es que desde su establecimiento en 2003, la Fiscalía de la CPI ha desarrollado exámenes preliminares en otras diez situaciones. De estas últimas, tres son de América Latina (Colombia, Honduras y Venezuela), cinco de Asia (Afganistán, Georgia, Corea, Irak y Palestina) y dos de África (Guinea y Nigeria) ${ }^{11}$. Además, el 25 de noviembre de 2011 se presentó una comunicación por presuntos delitos de lesa humanidad y crímenes de guerra cometidos en México entre 2006 y 2012 (alegando en particular la presunta responsabilidad penal del entonces presidente de México, Felipe Calderón), que hasta el momento no ha sido expresamente desestimada por la Fiscalía de la CPI, ni ha dado lugar al inicio de un examen preliminar $^{12}$.

\subsection{Venezuela}

En relación con la situación en Venezuela, la Fiscalía de la CPI presentó el 9 de febrero de 2009 sus conclusiones sobre un examen preliminar, que trataba de las alegaciones de delitos de lesa humanidad y crímenes de guerra cometidos por el gobierno venezolano contra oponentes políticos, desde la entrada en vigor del Estatuto de la CPI (Estatuto de Roma, ER) el 1 de julio de 2002. Las alegaciones -además de referirse a hechos sobre los que la CPI no tenía jurisdicción por haberse producido durante e inmediatamente después del intento de golpe de Estado de abril de 2002- incluían 45 casos de asesinato, 39 a 44 de detención arbitraria, 42 de tortura y numerosos más de persecución ${ }^{13}$. En dichas conclusiones, la Fiscalía afirmó que la información presentada por los denunciantes (y la obtenida a través de fuentes adicionales como los informes de la Comisión Interamericana de Derechos Humanos), no eran suficientes para afirmar la existencia de un fundamento razonable para creer que había existido en Venezuela un conflicto

11 Véase la sección de exámenes preliminares de la Fiscalía dentro de la página web de la CPI: [en línea] <http://www. icc-cpi.int/en_menus/icc/structure\%20of\%20the\%20court/office\%20of\%20the\%20prosecutor/comm\%20and\%20 ref/Pages/communications\%20and\%20referrals.aspx.> [consulta: 27 de enero de 2014].

Véase la noticia [en línea] <http://latino.foxnews.com/latino/news/2011/10/12/activists-ask-icc-to-try-mexicos-calderon-over-drug-war-carnage/> [consulta: 27 de enero de 2014].

13 Fiscalía de la CPI. OTP response to communications concerning Venezuela, de 9 de febrero de 2006. Disponible [en línea] <http://www.icc.cpi.int/en_menus/icc/structure\%20of\%20the\%20court/office\%20of\%20the\%20prosecutor/comm\%20and\%20ref/pe-cdnp/venezuela/Pages/venezuela.aspx.> [consulta: 27 de enero de 2014]. 
armado o un ataque sistemático o generalizado contra la población civil en ejecución de una política del gobierno venezolano ${ }^{14}$.

\subsection{Honduras}

A diferencia del examen preliminar sobre Venezuela, el examen preliminar sobre Honduras sigue en curso. De hecho, actualmente la Fiscalía de la CPI continúa analizando si existen fundamentos razonables para afirmar que se han producido delitos de lesa humanidad ${ }^{15}$.

El análisis de la Fiscalía de la CPI se ha centrado en los actos de violencia cometidos en tres momentos temporales. En primer lugar, aquellos que rodearon la expulsión del poder del entonces presidente Manuel Zelaya el 28 de junio de 2009. En segundo lugar, los producidos desde dicha expulsión hasta las elecciones generales celebradas en noviembre de 2009, incluyendo aquellos que rodearon las manifestaciones multitudinarias que se sucedieron en distintas ciudades de Honduras en su favor, la investidura de Roberto Micheletti por el Congreso de Honduras como presidente provisional, la aprobación del estado de emergencia y la emisión de varios decretos que restringieron las libertades de movimiento y reunión y autorizaron a las Fuerzas Armadas a detener a quienes se encontraban en lugares públicos tras el toque de queda, y a registrar los domicilios privados sin una orden judicial. En tercer lugar, la violencia ocurrida tras las elecciones de noviembre de 2009 en las que Porfirio Lobo resultó victorioso, siendo investido presidente en enero de $2010^{16}$.

Desde el inicio de su examen preliminar en el segundo semestre de 2009, la Fiscalía de la CPI ha buscado información en múltiples fuentes, incluyendo la Comisión de la Verdad y Reconciliación establecida en abril de 2010 por el nuevo presidente Porfirio Lobo (cuyo informe fue emitido en julio de 2011), la Comisión de la Verdad alternativa creada por organizaciones hondureñas de defensa de los Derechos Humanos (cuyo informe fue publicado el 3 de octubre de 2012), la Comisión Interamericana de Derechos Humanos $(\mathrm{CIDH})$, la Oficina del Alto Comisionado para las Naciones Unidas y varias organizaciones no gubernamentales de ámbito nacional e internacional ${ }^{17}$.

Según la información obtenida por la Fiscalía de la CPI, entre 3.000 y 4.500 personas fueron arbitrariamente arrestadas desde junio de 2009 hasta noviembre del mismo año, normalmente por un tiempo no superior a 24 horas $^{18}$.

En ocasiones, las detenciones fueron acompañadas por abusos verbales y físicos, así como por actos de tortura y maltrato ${ }^{19}$. Además, entre 13 y 32 personas fueron asesinadas en dicho período, incluyendo algunos activistas que se opusieron al golpe de Estado y varios manifestantes que fueron víctimas de un excesivo uso de la fuerza por miembros del Ejército y la Policía ${ }^{20}$. Finalmente, también se identificaron algunos actos de tortura (incluyendo los cometidos contra dos periodistas mientras se encontraban en prisión ${ }^{21}$ ), al menos dos casos de violación de mujeres

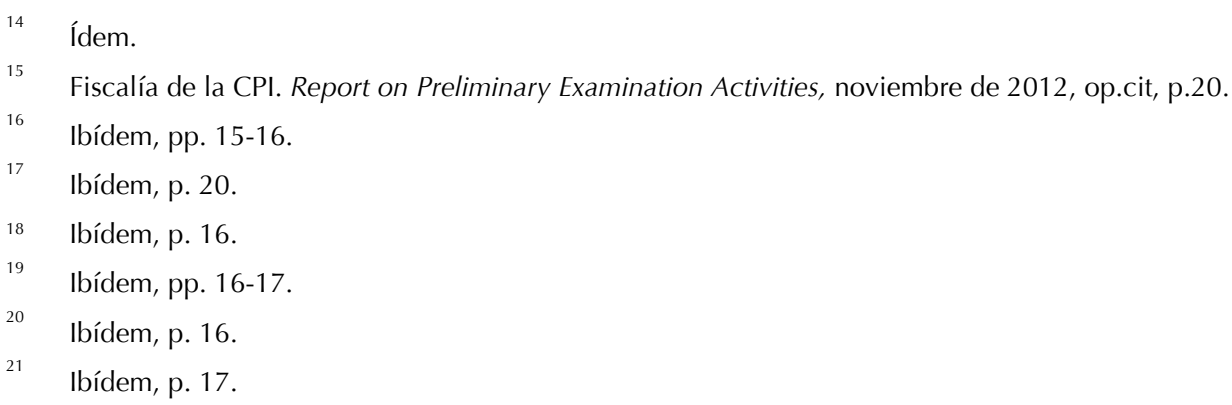


detenidas, la deportación a Costa Rica del ex presidente Manuel Zelaya y su ministra de asuntos exteriores Patricia Rodas, y varios incidentes de amenazas y agresiones contra defensores de derechos humanos, periodistas y líderes comunitarios ${ }^{22}$.

En su informe general sobre exámenes preliminares de noviembre de 2013, la Fiscalía de la CPI ha concluido que no es posible observar en estos hechos de violencia la generalidad o sistematicidad que requieren los delitos de lesa humanidad. En relación con la falta de generalidad, la Fiscalía afirma que las víctimas de asesinatos, torturas, violencia sexual y detenciones de larga duración, o en graves condiciones, fueron relativamente pocas, en comparación con el amplio conjunto de la población que se opuso a la expulsión de Manuel Zelaya y que fue presuntamente objeto de ataque ${ }^{23}$. Por su parte, con respecto a la falta de sistematicidad, la Fiscalía afirma que las serias violaciones arriba señaladas no parecen haber ocurrido de manera organizada y siguiendo un patrón regular de conducta ${ }^{24}$.

Sin embargo, la Fiscalía de la CPI ha decidido mantener abierto su examen preliminar debido a nuevas alegaciones que afirman que el notable incremento de la violencia en Honduras tras las elecciones presidenciales de noviembre de 2009, ha generado la comisión de delitos de lesa humanidad en los últimos años. En consecuencia, el actual análisis de la Fiscalía se centra en determinar si la violencia existente en Honduras desde la investidura de Porfirio Lobo como presidente en enero de 2010 puede haber escalado en un patrón de hechos de violencia calificables como delitos de lesa humanidad conforme al artículo del 7 del ER, en cuyo caso sería necesario revisar, sobre esta base, las conclusiones alcanzadas con respecto al período inmediatamente anterior ${ }^{25}$.

\subsection{Colombia}

El examen preliminar sobre la situación en Colombia es, sin duda, el más extenso de los desarrollados hasta la fecha en América Latina (2005-2013) y es el que ha conocido de un mayor número de actividades de obtención de información y seguimiento por parte de la Fiscalía de la $\mathrm{CPI}$. De hecho, semanas después de que la Corte Constitucional de Colombia se pronunciara en mayo de 2006 sobre la constitucionalidad de la Ley de Justicia y Paz (pieza clave del proceso de desmovilización de los grupos paramilitares) ${ }^{26}$, la Fiscalía de la CPI anunció que desde el año 2005 venía desarrollando un examen preliminar sobre la situación en Colombia ${ }^{27}$. Al año siguiente, en octubre de 2007, y posteriormente en agosto de 2008, el entonces Fiscal Jefe de la CPI, Luis Moreno-Ocampo, realizó importantes visitas al país ${ }^{28}$. En el año 2010, el Fiscal General y una amplia representación de la Sala de Casación Penal de la Corte Suprema de Justicia viajaron hasta la sede de la Fiscalía de la CPI en la Haya ${ }^{29}$, lo que fue seguido por una

\footnotetext{
22 Ídem.

23 Ibídem, p. 18.

24 Ídem.

25 Ibídem, p. 20.

26 Corte Constitucional de Colombia. Sentencia de 18 de mayo de 2006. C-370/2006. Véase también, ARVELO, J.E. "International Law and Conflict Resolution in Colombia: Balancing Peace and Justice in the Paramilitary Demobilization Process". Georgetown Journal of International Law, Vol. 77, 2006, pp. 411 y ss.

$27 \quad$ Véase, la página oficial de la Fiscalía de la CPI sobre la situación en Colombia: [en línea] <http://www.icc-cpi.int/ en_menus/icc/structure\%20of\%20the\%20court/office\%20of\%20the\%20prosecutor/comm\%20and\%20ref/pe-ongoing/colombia/Pages/colombia.aspx> [consulta: 4 de marzo de 2014]. Ídem.

OLÁSOLO, Héctor. La Función de la Corte Penal Internacional..., op.cit, pp. 50-52.
} 
nueva y última visita de Luis Moreno Ocampo a Colombia en septiembre de $2011^{30}$.

En diciembre de $2011^{31}$, la Fiscalía de la CPI publicó un primer informe relativo al desarrollo de su examen preliminar sobre dicho Estado, en el que además de explicar que había recibido hasta el momento 86 comunicaciones $^{32}$, informaba de la adopción de las siguientes medidas:

La Oficina mantiene un diálogo constante con el gobierno de Colombia y ha recibido recientemente información actualizada sobre las actuaciones de las autoridades judiciales nacionales competentes. Más recientemente, el 21 de septiembre de 2011, el Fiscal se encontró con la nueva Fiscal General de Colombia, Vivian Morales. La autoridades colombianas han transmitido posteriormente nueva información actualizada sobre las actuaciones de JPL JJusticia y Paz] [...] La Oficina ha intervenido en discusiones públicas sobre la aplicación del principio de complementariedad en Colombia. En una reunión bianual con las ONGs mantenida el 20 de octubre de 2010, la Oficina sostuvo una sesión sobre la complementariedad en el marco del examen preliminar en Colombia, con panelistas comentando la respuesta de las autoridades colombianas a la lucha contra la impunidad. La sesión se centró específicamente en torno a las actuaciones de JPL [...] En mayo de 2011 en Londres, la Fiscalía participó en una conferencia de alto nivel, en la que estuvieron presentes un buen número de expertos, funcionarios colombianos, magistrados y representantes de ONGs, y que generó un saludable debate sobre el papel de la Oficina en el fortalecimiento del principio de complementariedad en Colombia [...] La Oficina continuará examinando la situación y las actuaciones nacionales en Colombia. En este contexto, y conforme al principio de complementariedad positiva que ha adoptado, la Oficina da la bienvenida a los actuales esfuerzos del gobierno colombiano de buscar mayor apoyo internacional para las actuaciones judiciales nacionales y de promover la cooperación, tal y como ha explicado el actual presidente de Colombia D. Juan Manuel Santos, durante la novena Asamblea de los Estados Partes en diciembre de 2010 [...] El nombramiento del juez español Baltasar Garzón, que ha trabajo para la Oficina como asesor en la Misión de Apoyo del Proceso de Paz en Colombia de la Organización de los Estados Americanos (OEA) es un ejemplo de la cooperación entre los Estados Partes, las organizaciones internacionales y la Oficina ${ }^{33}$.

En noviembre de 2012, bajo la dirección de la actual Fiscal Jefe de la CPI, Fatou Bensouda ${ }^{34}$, la Fiscalía de la CPI presentó un segundo informe sobre el examen preliminar de la situación en Colombia. En el mismo, la Fiscalía subrayó la existencia de un fundamento razonable para creer que los distintos actores involucrados en el conflicto armado habían cometido delitos de lesa humanidad desde el 1 de noviembre de 2002, fecha de entrada en vigor del ER para tal país ${ }^{35}$. Asimismo, la Fiscalía confirmó que había venido recogiendo información sobre el desarrollo de las actuaciones nacionales con respecto a estos delitos, a efectos de determinar en el marco de su análisis de admisibilidad sobre la situación en Colombia, si las mismas: (i) incluían a quienes

Fiscalía de la Corte Penal Internacional. Report on the Preliminary Examination Activities, de 13 de diciembre de 2011. Disponible [en línea] <http://www.icc-cpi.int/NR/rdonlyres/63682F4E-49C8-445D-8C13-F310A4F3AEC2/284116/OTP ReportonPreliminaryExaminations13December2011.pdf> [consulta: 4 de marzo de 2014], párr. 85.

Ibídem, párr. 85.

Ibídem, párr. 61.

Fiscalía de la CPI. Report on the Preliminary Examination Activities, de 13 de diciembre de 2011, op.cit., párrs. 83-86.

La nueva Fiscal Jefe de la CPI tomó posesión de su cargo el 15 de junio de 2012.

Fiscalía de la CPI. Situación en Colombia, Reporte Intermedio, 12 de noviembre de 2012, párrs. 5-10. Disponible en la página oficial de la Fiscalía de la CPI: [en línea] <http://www.icc-cpi.int/en_menus/icc/structure\%20 of $\% 20$ the $\% 20$ court/office $\% 20$ of $\% 20$ the $\% 20$ prosecutor/comm $\% 20$ and $\% 20$ ref/colombia/Pages/Situation-in-Colombia-Interim-Report.aspx> [consulta: 27 de enero de 2014]. 
tenían presuntamente una mayor responsabilidad en su comisión (máximos responsables); y (ii) se estaban Ilevando a cabo de manera realmente genuina (es decir, sin adolecer de una falta de disposición o de capacidad por parte del Estado colombiano $)^{36}$.

Recientemente, en su informe general sobre exámenes preliminares de noviembre de 2013, la Fiscalía de la CPI ha ratificado lo señalado en su segundo informe específico sobre Colombia de noviembre de $2012^{37}$. Además, ha subrayado que, si bien las autoridades colombianas han tomado medidas para priorizar las investigaciones y enjuiciamientos contra las personas más responsables, así como para incluir los delitos de violencia sexual y desplazamiento forzado, es necesario continuar analizando el progreso de las actuaciones nacionales a los efectos de determinar la admisibilidad o no de la situación en Colombia ${ }^{38}$.

\subsection{Valoración inicial}

Los exámenes preliminares desarrollados hasta el momento por la Fiscalía de la CPI con respecto a las situaciones en Colombia, Honduras y Venezuela, muestran que las actividades de la Fiscalía de la CPI son mucho más cercanas a América Latina de lo que podría parecer en un primer momento.

Además, en particular en el caso colombiano, se refleja con nitidez cómo la Fiscalía de la $\mathrm{CPI}$ ha recurrido sistemáticamente a múltiples fuentes de información, visitas en el terreno, canales diplomáticos y medios de comunicación para alertar a la comunidad internacional sobre los delitos cometidos y la impunidad de sus presuntos autores. Con ello se ha incentivado a las autoridades nacionales para que cumplan con sus obligaciones de persecución penal, de manera independiente, imparcial y dentro de un plazo razonable, lo que evitaría la apertura de una investigación formal por parte de la propia CPI.

\section{El fenómeno de la lesa humanidad en Colombia según la Fiscalía de la CPI}

El artículo 7 del ER define los delitos de lesa humanidad como cualquiera de los actos enumerados en su párrafo primero ${ }^{39}$, siempre que "se cometa como parte de un ataque generalizado o sistemático contra una población civil y con conocimiento de dicho ataque" ${ }^{\prime 40}$. El párrafo segundo de esta misma disposición añade que "por 'ataque contra una población civil' se entenderá una línea de conducta que implique la comisión múltiple de actos mencionados en el párrafo 1 contra una población civil, de conformidad con la política de un Estado o de una organización de cometer ese ataque o para promover esa política" ${ }^{\prime 41}$. En consecuencia, se puede afirmar que según el ER, el fenómeno de la lesa humanidad se caracteriza por situaciones en las que se desarrollan dinámicas de violencia sistemática y/o generalizada contra el conjunto -o contra algunos sectores-, de la población civil de un territorio, detrás de las cuales se encuentran

36 íbídem, párrs. 11-22.

37 Fiscalía de la CPI. Report on Preliminary Examination Activities, noviembre 2013, op. cit., pp. 23-28.

38 Ídem.

39 El párrafo 1 del artículo 7 del ER enumera los siguientes actos: asesinato, exterminio, esclavitud, deportación o traslado forzoso, encarcelamiento o privación grave de libertad en violación del normas fundamentales de derecho internacional, tortura, violación, esclavitud sexual, prostitución forzada, embarazo forzado, esterilización forzada u otras formas de violencia sexual de comparable gravedad, persecución de un grupo o colectividad con identidad propia por motivos universalmente reconocidos como inaceptables conforme al derecho internacional, desaparición forzosa, apartheid y otros tratos inhumanos de carácter similar que causen intencionalmente grandes sufrimientos o atenten gravemente contra la integridad física o la salud mental o física. 
políticas de ciertos Estados u organizaciones ${ }^{42}$.

En su informe de 12 de noviembre de 2012 (aquel que analiza en mayor profundidad hasta el momento los hechos de violencia cometidos en Colombia desde el 1 de noviembre de 2012), la Fiscalía de la CPI estudia cómo se ha desarrollado el fenómeno de la lesa humanidad en Colombia, Ilegando a la conclusión de que existe un fundamento razonable para creer que, desde el 1 de noviembre de 2002, todos los actores implicados en el conflicto armado (FARC, Ejército de Liberación Nacional -en adelante ELN-, grupos paramilitares, Fuerzas Armadas y de Policía de Colombia) han cometido delitos de lesa humanidad ${ }^{43}$.

Frente a las FARC, al ELN y a los grupos paramilitares, la Fiscalía de la CPI encuentra motivos fundados de la comisión de asesinatos, desplazamientos forzados, detenciones arbitrarias, torturas, violación y otros abusos sexuales ${ }^{44}$. Según la Fiscalía, las FARC y en menor medida el ELN, centraron sus operaciones militares en obtener y ejercitar el control sobre partes del territorio colombiano mediante ataques sistemáticos y generalizados contra la población civil, a efectos de obtener de las mismas ventajas políticas, financieras y de control social ${ }^{45}$.

En relación con los grupos paramilitares, la Fiscalía de la CPI afirma que, al prestar su asistencia al ejército colombiano en la lucha contra las FARC y el ELN, cometieron actos de violencia como parte integral de su estrategia de actuación ${ }^{46}$. La Fiscalía subraya las conclusiones de la CIDH relativas a que unidades paramilitares han estado involucradas en asesinatos masivos de civiles, y en el asesinato selectivo de líderes sociales, sindicalistas, defensores de derechos humanos, actores judiciales, y periodistas ${ }^{47}$. También han participado en actos de tortura, intimidación, y acciones violentas dirigidas a desplazar a comunidades enteras. Para la Fiscalía de la CPI, la política de atacar a civiles parece haber estado diseñada para terminar con cualquier vínculo real o sospechado entre aquellos y la guerrilla ${ }^{48}$.

La Fiscalía de la CPI señala que cuarenta y cinco dirigentes de la población desplazada fueron asesinados entre 2002 y 2011, y los familiares de muchos líderes comunitarios han sido atacados deliberadamente para evitar que soliciten la restitución de la tierra ${ }^{49}$. Según la Fiscalía, ataques similares se han llevado a cabo contra comunidades afro-americanas, debido a que habitan regiones de Colombia ricas en recursos minerales, que son consideradas por los grupos armados como de importancia estratégica para la producción y tráfico de narcóticos (las cifras varían entre los 3.166 asesinatos de indígenas, sindicalistas, profesores, defensores de derechos humanos, autoridades locales y civiles reconocidos por el Programa Presidencial de Derechos

42 Véase a este respecto la definición de los delitos de lesa humanidad contenida en la decisión de la Sala de Cuestiones Preliminares II de apertura de la investigación en la situación de Kenia; ICC. (Pre Trial Chamber II). Situation in Kenya, Decision Pursuant to Article 15 of the Rome Statute on the Authorization of an Investigation into the Situation in the Republic of Kenya, ICC-01/09-19, de 31 de marzo de 2010. Véase también, el voto particular del magistrado Hans Peter Kaul sobre el contenido de la definición de los delitos de lesa humanidad. Desafortunadamente, la Sala de Primera Instancia II no realizó ningún tipo de análisis sobre la definición de los delitos de lesa humanidad en su reciente sentencia de 18 diciembre de 2012 en el caso contra Matheiu Ngudjol Chui; ICC. (Pre Trial Chamber II). Prosecutor vs Mathieu Ngudjolo Chui, Jugement rendu en application del'article 74 du Statute, ICC-01/04-02/12-3, de 18 de diciembre de 2012.

Fiscalía de la CPI. Situación en Colombia, Reporte Intermedio, op. cit., párrs. 5-10.

Ibídem, párrs. 5 -7 y 38-91.

Ibídem, párrs. 5, 6 y 41.

Ibídem, párrs. 7 y 42.

Ibídem, párr. 42.

Ídem.

Ibídem, párr. 43. 
Humanos, y los 6.040 registrados por fuentes no gubernamentales) ${ }^{50}$. Asimismo, la Fiscalía de la CPI subraya que entre 2005 y 2010 más de 50.000 miembros de comunidades indígenas fueron desplazados por las FARC, el ELN y los grupos paramilitares ${ }^{51}$.

La Fiscalía de la CPI pone particular énfasis en que la violación y otras formas de violencia sexual han sido un fenómeno recurrente en el conflicto colombiano, el cual ha generado cerca de 35.000 víctimas entre los años 2001 y 2009 en los departamentos de Antioquia, Cauca, Córdoba, Arauca, Nariño, Tolima, Risaralda, Quindío, Palmira (Valle del Cauca), Norte de Santander, y el Valle ${ }^{52}$. Las víctimas de estos delitos incluyen a mujeres y niñas que: (i) han sido reclutadas forzosamente; (ii) son familiares de miembros de los grupos armados; (iii) son percibidas como relacionadas con miembros de los grupos contrarios; (iv) obstruyen el reclutamiento forzado de sus hijos e hijas; (v) pertenecen a comunidades indígenas; (vi) tienen una orientación sexual cuestionada $^{53}$; (vii) son presuntas portadoras de enfermedades de transmisión sexual como el SIDA; (viii) son miembros de organizaciones defensoras de derechos humanos; y (ix) rechazan obedecer las instrucciones del actor armado con mayor influencia en el área ${ }^{54}$. En cuanto a los motivos identificados para la comisión de estos actos de violencia sexual, se encuentran el promover el terror dentro de las comunidades para facilitar su control militar, el obligar a la gente a huir para facilitar la adquisición de territorio, la venganza, la acumulación de "trofeos de guerra", la explotación de las víctimas como esclavas sexuales, y el menoscabo del honor del enemigo ${ }^{55}$. Para la Fiscalía de la CPI, la comisión a gran escala de estos delitos, el gran número de víctimas y la manera organizada de su comisión muestran el carácter generalizado y sistemático de los actos de violencia sexual cometidos por miembros de las FARC, el ELN y los grupos paramilitares contra la población civil colombiana ${ }^{56}$.

Finalmente, en relación con los actores estatales, la Fiscalía de la CPI Ilama la atención sobre el fenómeno de los llamados "falsos positivos", que ha provocado el asesinato por miembros de las Fuerzas Armadas, actuando en ocasiones en connivencia con miembros de grupos paramilitares y civiles, de miles de personas a quienes se hacía pasar por presuntos guerrilleros muertos en combate, para dar así una apariencia de mayor eficacia en la lucha frente a la guerrilla y para obtener con ello mayores recursos del Estado ${ }^{57}$. Para la Fiscalía de la CPI, los 1.669 casos actualmente investigados por la Fiscalía colombiana (cifra que podría incrementarse hasta los 2.896), proveen una base razonable para creer que se trata de delitos de lesa humanidad, Ilevados a cabo en ejecución de un política adoptada, al menos, al nivel de ciertas brigadas del Ejército colombiano, quedando por determinar si la misma pudo haberse extendido también a los más altos niveles del aparato del Estado de Colombia ${ }^{58}$.

\section{Consecuencias de la configuración de los delitos de lesa humanidad como crímenes internacionales de ius cogens}

Una vez analizadas las conclusiones de la Fiscalía de la CPI sobre el fenómeno de la lesa

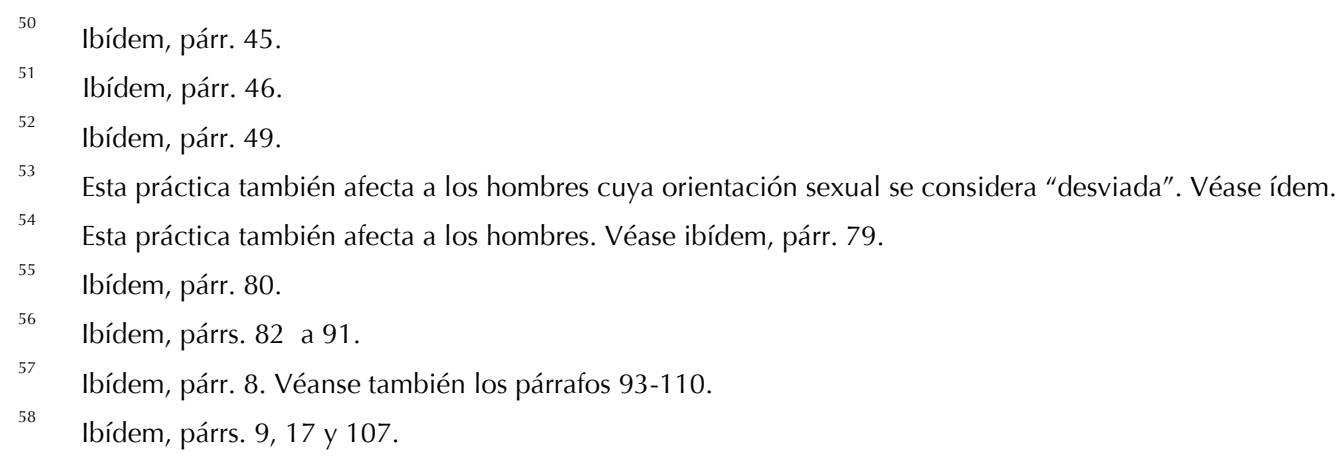


humanidad en Colombia, y la implicación en los delitos allí cometidos por los distintos actores implicados en el conflicto armado (FARC, ELN, grupos paramilitares/AUC, y Fuerzas Armadas y de Policía de Colombia) ${ }^{59}$, conviene detenernos a estudiar cuáles son las consecuencias derivadas de la actual configuración en el derecho internacional de los delitos de lesa humanidad, como crímenes internacionales de ius cogens.

En 1915, los gobiernos de Francia, Reino Unido y Rusia realizaron una declaración conjunta afirmando que Turquía había cometido delitos que afectaban a la "conciencia de la humanidad"60 contra cerca de 800.000 armenios que habitaban en su territorio. Al término de la Primera Guerra Mundial en 1918, el proyecto de Tratado de Sevres afirmaba el derecho de las potencias vencedoras a enjuiciar a los responsables de tales delitos, y la obligación de Turquía de entregar a los miembros del gobierno turco y de sus Fuerzas Armadas que los habían incitado ${ }^{61}$. El proyecto no llegó a entrar en vigor porque Estados Unidos y Japón se opusieron al mismo, al considerar que la categoría de delitos contra la conciencia de la humanidad no había sido definida a nivel internacional con anterioridad a la violencia ejercida contra los armenios residentes en Turquía ${ }^{62}$.

Sin embargo, fueron los Estados Unidos quienes veinticinco años después se convertirían en los grandes paladines del Tribunal Militar Internacional de Nüremberg (TMI), que fue establecido en 1945 a través del Tratado de Londres. El TMI juzgaría a los más altos dirigentes políticos y militares del régimen nazi por el delito de agresión y los crímenes de lesa humanidad y de guerra cometidos durante la Segunda Guerra Mundial ${ }^{63}$. Tras la sentencia proferida el 1 de octubre de 194664, la Asamblea General de las Naciones Unidas afirmó en su resolución 95 (I) de 11 de diciembre de 1946 los principios de derecho internacional reconocidos en el estatuto y sentencia del TMI (conocidos como "principios de Nüremberg") ${ }^{65}$, entre los que se encontraba el reconocimiento del carácter internacional de la categoría de los delitos de lesa humanidad ${ }^{66}$.

La resolución 95 (I) fue seguida por la resolución 177 (II) de 21 de noviembre de 1947, por la que se instruía a la recién creada Comisión de Derecho Internacional (CDI) que formulara y desarrollara los principios de Nüremberg y preparara un Código de Crímenes Internacionales ${ }^{67}$. En 1950, la CDI presentó a la Asamblea General su informe sobre los principios de Nüremberg, en el que se reconoce que aquellas situaciones en las que se producen múltiples actos de

59 Ibídem, párrs. 5-10.

60 Esta declaración se recoge en el memorándum armenio, presentado el 14 de marzo de 1919 por la delegación griega a la Commission on the Responsibilities of Authors of the War and on the Enforcement of Penalties, formada por los Estados aliados al final de la Primera Guerra Mundial. Este memorándum se encuentra en SCHWELB, Egon. "Crimes Against Humanity". British Yearbook of International Law, Vol. 23, No.8, 1949, pp. 178 y 181. Véanse también a este respecto entre otros, DADRIAN, Vahakn. "Genocide as a Problem of National and International Law: The World War I Armenian Case and Its Contemporary Legal Ramifications". Yale Journal of International Law, Vol.14, No.2, 1989; WILLIS, James. Prologue to Nuremberg: The Politics and Diplomacy of Punishing War Criminals of the First World War. Westport: Greenwood Press, 1982.

61 MATAS, David. "Prosecuting Crimes Against Humanity: The Lessons of World War I". Fordham International Journal, Vol.13, No.1, 1989.

62 BASSIOUNI, M.Cherif. Crimes against Humanity - Historical Evolution and Contemporary Application. Cambridge: Cambridge University Press, 2011, pp. 88-89. Ibídem, pp. 111-116.

Sentencia del Tribunal Militar Internacional de Nuremberg, de 1 de octubre de 1946. Año y medio después, el Tribunal Militar Internacional para el Lejano Oriente, dictaría su sentencia el 4 de noviembre de 1948.

Asamblea General de las Naciones Unidas, Resolución 95 (I), de 11 de diciembre de 1946. Ídem. 
violencia sistemática (o a gran escala) contra la población civil no son una cuestión meramente interna del Estado, sino que se convierten en un asunto de la comunidad internacional en su conjunto, pues menoscaban los valores básicos sobre los que se organiza la propia comunidad internacional ${ }^{68}$. Además, debido a que en su origen los delitos de lesa humanidad fueron cometidos a través de instituciones del Estado que daban a los mismos un "barniz de legalidad", también se incorporó el principio por el que la comisión de este tipo de delitos no depende de su prohibición en la normativa interna del Estado afectado, sino que por el contrario, la legislación nacional es considerada irrelevante a los efectos de determinar si dirigentes políticos o militares incurrían en delitos de lesa humanidad ${ }^{69}$.

A pesar de que la Asamblea General de las Naciones Unidas en su resolución 488 (V) de 12 de diciembre de $1950^{70}$ no adoptó formalmente la versión más elaborada de los principios Nüremberg presentada por la CDI en 1950 (invitando meramente a los Estados a formular observaciones al informe presentado por la $\mathrm{CDI})^{71}$, lo cierto es que -tal y como ha afirmado M.C. Bassiouni-, la mayoría de la doctrina atribuye un valor determinante al informe de la CDI como prueba de que los principios de Nüremberg eran, ya en 1950, parte de la costumbre internacional o de los principios generales del derecho ${ }^{72}$.

Los artículos 7 (1) y 6 (1) de los Tribunales Penales Internacionales para la antigua Yugoslavia (1993) y Ruanda (1995), así como el artículo 7 del ER (1998), acogen la elaboración que había realizado el derecho internacional general al término de la Segunda Guerra Mundial, de la categoría de los delitos de lesa humanidad. Estas disposiciones reafirman que la comisión de dichos delitos da lugar a responsabilidad penal individual frente a la comunidad internacional en su conjunto, de manera que quienes incurren en estos comportamientos se convierten en "enemigos de la humanidad", lo que hace que puedan ser investigados y enjuiciados por cualquier Estado actuando en nombre de la Comunidad Internacional (por el principio de justicia universal) o por un tribunal penal internacional creado por aquella a tales efectos ${ }^{73}$.

En consecuencia, es hoy comúnmente aceptado que, al menos desde la aprobación de ER en $1998^{74}$, la categoría de los delitos de lesa humanidad se ha convertido en parte fundamental de aquel conjunto de normas de carácter consuetudinario (conocidas como normas de ius cogens) que, según la Corte Internacional de Justicia, tiene un valor superior a cualquier otra norma

ILC Commission Report. Principles of International Law Recognized in the Charter of the Nuremberg Tribunal and in the Judgment of the Tribunal, U.N. Doc. No. A/1316 (A/5/12), párrs. 95-127, En: Anuario de la Comisión de Derecho Internacional (Yearbook de la International Law Commission), Vol. 2, 1950. Ídem.

$70 \quad$ Asamblea General de las Naciones Unidas. Resolución 488 (V), de 12 de diciembre de 1950.

71 Ídem.

72 BASSIOUNI, M. Cherif. Crimes against Humanity..., op. cit., p. 174.

73 Ibídem, pp. 177-204. En su sesión del año 2005 celebrada en Cracovia, el Instituto de Derecho Internacional afirmó la competencia universal sobre los delitos de lesa humanidad. Como ha sido señalado a este respecto, "[e]l DI General es en este punto permisivo, siendo una cuestión de soberanía legislativa de cada Estado asumir el principio de universalidad, modular su alcance y condicionar su aplicación, atendiendo a su implicación en la protección de los derechos humanos y sus consecuencias de política exterior, en particular su incidencia sobre la satisfacción de otros objetivos". Véase REMIRO BROTONS, Antonio (et. al.). Derecho Internacional. Valencia: Tirant lo Blanch, 2007, p. 134.

Véase a este respecto, entre otros, BASSIOUNI, M. Cherif. "Accountability for Violations of International Humanitarian Law and Other Serious Violations of Human Rights". En: BASSIOUNI, M. Cherif. Post-conflict Justice. Ardsley: Transnational Publishers, 2002, pp. 3 y ss. y; BENAVIDES, Farid. Justicia en Épocas de Transición, Conceptos, Modelos, Debates, Experiencias. Barcelona: Institut Catalá International per la Pau, 2011, pp. 24-25. 
internacional, incluidas las acordadas por las partes en tratados internacionales ${ }^{75}$. Con ello, la tensión entre quienes consideran que la exigencia de responsabilidad penal es un ideal que hace imposible el logro de la paz a corto y medio plazo (ya que las partes en un proceso de negociación pierden todo incentivo para dejar el poder y las armas) ${ }^{76}$, y quienes entienden que la llamada realpolitik conduce a la impunidad (porque los dirigentes de gobiernos y grupos armados de oposición negocian su exención de responsabilidad, a cambio de acuerdos de paz inmediatos que fracasan en generar una paz duradera $)^{77}$, ha resultado en la consolidación en el derecho internacional de un modelo basado en la exigencia de sanción penal y la eliminación de la impunidad en relación con el fenómeno de la lesa humanidad ${ }^{78}$.

Este modelo, construido sobre los principios de Nüremberg y consagrado en los estatutos del TPIY, el TPIR y la CPI, subraya la necesidad moral y legal de combatir la impunidad, al tiempo que afirma que la justicia penal es una condición necesaria para obtener una paz sostenible en el tiempo, para alcanzar la reconciliación, y para promover la democracia (minimizando con ello el riesgo de caos y anarquía $)^{79}$. Con ello, los Estados que conforman la comunidad internacional han aceptado que en situaciones de violencia sistemática o generalizada contra la población civil, los valores paz y justicia deben ir necesariamente de la mano, sin que el segundo pueda quedar desplazado por el primero ${ }^{80}$.

En este contexto, por justicia no se entiende únicamente el derecho de las víctimas y la sociedad en general a conocer la verdad sobre los factores políticos, económico-financieros, sociales e institucionales que favorecieron la espiral de violencia contra la población civil, o el derecho de las víctimas a una reparación integral ${ }^{81}$. Por justicia en este contexto se entiende la declaración

75 Según la definición dada por la Corte Internacional de Justicia en el caso de Bélgica con España, relativo a la Barcelona Traction, Light and Power Company, Limited (C.I.J., Rec. 1970), párrs. 33 y 34: "[...] debe establecerse, en particular, una distinción esencial ente las obligaciones de los Estados hacia la comunidad internacional en su conjunto y las que nacen respecto de otro Estado en el campo de la protección diplomática. Por su propia naturaleza, las primeras conciernen a todos los Estados. Dada la importancia de los derechos en cuestión, puede considerarse que todos los Estados tienen un interés jurídico en que tales derechos sean protegidos; las obligaciones de que se trata son obligaciones erga omnes".

OSIEL, Mark. "Why Prosecute? Critics of Punishment for Mass Atrocity". Human Rights Quarterly, Vol. 22, 2000.

MATWIJKIW, Anja. "A Philosophical Perspective on Accountability and Post-Conflict Justice: Setting Up the Premise". En: BASSIOUNI, M.Cherif. Post-conflict Justice..., op.cit, pp. 155 y ss.

BASSIOUNI, M.Cherif. Accountability for Violations... op. cit., pp. 3 y ss; y BENAVIDES, Farid. Justicia en Épocas... op. cit., pp. 24-25.

MATWIJKIW, Anja. A Philosophical Perspective... op. cit., pp. 155 y ss, y BENAVIDES, Farid. Justicia en Épocas... op. cit., p. 25.

Ídem.

Véase en este sentido, por ejemplo, ICC [PTC I]. The Prosecutor vs Germain Katanga and Mathieu Ngudjolo Chui, Decision on the Set of Procedural Rights Attached to Procedural Status of Victim at the Pre-Trial Stage of the Case, 13 de mayo de 2008, ICC-01/04-01/07-474. Véase asimismo, la amplia jurisprudencia de la Corte IDH en relación con los derechos de las víctimas a la verdad, y a la justicia, tal y como ha sido desarrollada en particular en los casos: Corte IDH. Caso Velásquez Rodríguez vs. Honduras. Fondo. Sentencia de 29 de julio de 1988. Serie C No. 7, párrs. 162-166 y 174; caso Bamaca Velasquez vs. Guatemala. Fondo. Sentencia de 25 de noviembre de 2000. Serie C No 70, párr. 201, caso Barrios Altos vs. Perú. Fondo. Sentencia de 14 de marzo de 2001. Serie C No 75 , párr. 48; caso Comunidad Moiwana vs. Suriname. Excepciones Preliminares, Fondo, Reparaciones y Costas. Sentencia de 15 de junio de 2005. Serie C No. 124, párr. 204; caso Masacre de Mapiripán vs. Colombia. Excepciones Preliminares, Fondo, Reparaciones y Costas. Sentencia de 15 de septiembre de 2005. Serie C No 13, párr. 297; caso Almonacid Arellano y otros vs. Chile. Excepciones Preliminares, Fondo, Reparaciones y Costas. Sentencia de 26 de septiembre de 2006. Serie C No. 154, párrs. 148 y ss.; caso Vargas Areco vs. Paraguay. Fondo. Sentencia de 26 de septiembre de 2006. Serie C No. 155, párrs. 153 y ss. y; caso La Cantuta vs. Perú. Fondo, Reparaciones y Costas. Sentencia de 29 de noviembre de 2006. Serie C No. 162, párr. 222. 
y ejecución de la responsabilidad penal derivada del fenómeno de la lesa humanidad ${ }^{82}$.

Este principio ha sido afirmado en los casos Barrios Altos, Almonacid Arellano, La Cantuta, Gomes Lund, Gelman y El Mozote por la jurisprudencia constante de la Corte Interamericana de Derechos Humanos (Corte IDH) sobre la incompatibilidad sustantiva entre las normas de amnistía y las obligaciones de los Estados de investigar y enjuiciar a los responsables de graves violaciones de derechos humanos ${ }^{83}$.

En particular, en el caso de El Mozote, la Corte IDH analizó la cuestión relativa a si el artículo 6.5 del Protocolo II adicional a los Convenios de Ginebra de 1949 podría justificar en ciertas ocasiones "la emisión de leyes de amnistía cese de las hostilidades en los conflictos armados de carácter no internacional para posibilitar el retorno a la paz" ${ }^{14}$. La respuesta de la Corte IDH no deja lugar a dudas:

\begin{abstract}
Por consiguiente, puede entenderse que el artículo 6.5 del Protocolo II adicional está referido a amnistías amplias respecto de quienes hayan participado en el conflicto armado no internacional o se encuentren privados de libertad por razones relacionadas con el conflicto armado, siempre que no se trate de hechos que, como los del presente caso, cabrían en la categoría de crímenes de guerra e, incluso, en la de crímenes contra la humanidad ${ }^{85}$.
\end{abstract}

También la Fiscalía de la CPI ha afirmado este principio en los distintos documentos de política criminal que ha elaborado hasta el momento. En estos, la Fiscalía subraya la inexorable necesidad de persecución penal de los "máximos responsables" de dinámicas de violencia sistemática o generalizada frente a la población civil, entendiendo por tales a los dirigentes políticos y militares de las instituciones del Estado y las organizaciones involucradas ${ }^{86}$.

Al referirse a los máximos responsables, los documentos de política criminal de la Fiscalía no se pronuncian expresamente respecto a si el derecho internacional admite o no un tratamiento diverso (por ejemplo, la imposición de medidas de naturaleza no penal como las sanciones disciplinarias o las desvinculaciones administrativas) para quienes no entran en la categoría de máximos responsables ${ }^{87}$. Ahora bien, la propia Fiscalía de la CPI ha afirmado recientemente que: "La Fiscalía funciona de acuerdo a un criterio de dos componentes en la lucha contra la impunidad. Por un parte iniciará actuaciones contra los líderes que sean máximos responsables de los crímenes. Por otra parte, promoverá actuaciones nacionales, en la medida de lo posible, contra autores de menor rango o colaborará con la comunidad internacional para garantizar que los infractores sean Ilevados ante la justicia por otros medios ${ }^{\prime \prime 8}$. De manera que incluso cuando

82 Ídem. Véase también a este respecto, AMBOS, Kai. El marco jurídico de la justicia de transición. Bogotá: Temis, 2008.

83 Corte IDH. Caso Barrios Altos vs. Perú, op.cit, párr. 41; caso Almonacid Arellano y otros vs. Chile, op.cit, párr. 114; caso La Cantuta vs. Perú, op.cit, párr. 168; caso Gomes Lund y otros (Guerrilha do Araguaia) vs. Brasil. Excepciones Preliminares, Fondo, Reparaciones y Costas. Sentencia de 24 de noviembre de 2010. Serie C No. 209, párr. 147; caso Gelman vs. Uruguay. Fondo y Reparaciones. Sentencia de 24 de febrero de 2011. Serie C No. 221, párrs. 225-229 y 232; caso Masacres de El Mozote y lugares aledaños vs. El Salvador. Fondo, Reparaciones y Costas. Sentencia de 25 de octubre de 2012. Serie C No. 252, párr. 286. 
se tratara de infractores de menor rango, la Fiscalía "vería con preocupación toda medida que pareciera diseñada para proteger u obstaculizar el establecimiento de la responsabilidad penal de personas por crímenes de la competencia de la Corte" ${ }^{\prime 89}$. En este mismo sentido, la Sala de Apelaciones de la CPI ya ha dejado entrever en su decisión de 13 de julio de 2006, que el régimen aplicable a los máximos responsables podría ser también aplicable a quienes no son parte de dicha categoría ${ }^{90}$.

En un escenario en el que las políticas de perdón y olvido son contrarias a un derecho internacional informado por el principio "no hay paz sin justicia", la llamada justicia transicional (dirigida a favorecer el cese de situaciones de violencia sistemática o a gran escala y a promover procesos de normalización) sufre importantes limitaciones cuando se aplica al fenómeno de la lesa humanidad, al no encontrarse recogida en las normas de ius cogens ${ }^{91}$. Esto significa que medidas de exención de responsabilidad, de aplicación del principio de oportunidad generadoras de brechas de impunidad, de suspensión de la ejecución de penas, de ejecución de penas en regímenes especiales como el arresto domiciliario o de concesión de indultos a los máximos responsables de delitos de la lesa humanidad, si bien fueron aceptadas en el pasado (particularmente citado es el caso sudafricano de amnistía condicional hace ahora veinte años), violan hoy en día normas fundamentales de derecho internacional ${ }^{92}$.

Esta evolución no se ve alterada por la concesión a la Fiscalía de la CPI del principio de oportunidad para el ejercicio de la acción penal conforme a los "intereses de la justicia" ${ }^{\text {, ni }}$ ni por la facultad del Consejo de Seguridad de las Naciones Unidas para solicitar la suspensión de las investigaciones y enjuiciamientos de la CPI durante un plazo prorrogable de doce meses ${ }^{94}$.

Como señala el documento de política criminal de la Fiscalía de la CPI sobre el contenido del concepto "intereses de la justicia", este solo permite que la Fiscalía deje de iniciar una investigación, o no impute a alguno de los "máximos responsables", debido a la falta de gravedad de los hechos, a las dificultades de acceso a los elementos de prueba o a los problemas de protección de los testigos y las víctimas ${ }^{95}$.

En cuanto a los intereses de la paz, estos quedan encomendados por el artículo 16 del ER al Consejo de Seguridad de las Naciones Unidas ${ }^{96}$. El Consejo, tras determinar -conforme al capítulo VII de la Carta de las Naciones Unidas- la existencia de una amenaza a la paz, un

Ibídem, párr. 205.

ICC [PTC I]. Prosecutor v Thomas Lubanga Dyilo. Appeals Chamber, Judgment on the Prosecutor's appeal against the decision of Pre-Trial Chamber I entitled "Decision on the Prosecutor's Application for Warrants of Arrest", ICC01/04-169, de 13 de julio de 2007.

BENAVIDES, Farid. Justicia en Épocas... op. cit., p. 24-25.

Desde esta perspectiva se puede comprender el extenso debate generado en Colombia por la Ley de Justicia y Paz, que lejos de los supuestos de exención sustantiva o procesal de responsabilidad, permite la concesión a los máximos responsables de los grupos armados organizados al margen de la ley (en particular, grupos paramilitares), de una pena alternativa de entre 5 y 8 años tras un proceso penal y una condena basada en la confesión. Véase a este respecto las obras: AMBOS, Kai. Marco Jurídico... op. cit. y AMBOS, Kai. The Colombian Peace Process and the Principle of Complementarity of the International Criminal Court: An Inductive, Situation based-approach. Alemania: Springer, 2010.

Artículos 53 (1) y (2) del ER.

Artículo 16 del ER.

Fiscalía de la CPI. Policy Paper on the Interests of Justice, op.cit. Véase también, STAHN, Carsten. "Complementarity, Amnesties and Alternative Forms of Justice: Some Interpretative Guidelines for the International Criminal Court". Journal of International Criminal Justice, Vol. 3, 2005, pp. 695 y ss. 
quebrantamiento de la paz o un acto de agresión, podrá solicitar a la CPI que suspenda durante un período prorrogable de 12 meses, cualquier investigación o enjuiciamiento, en caso de que ello sea necesario para la salvaguarda de los "intereses de la paz"

Es por ello que el sorprendente voto concurrente del juez de la Corte IDH Diego García Sayán en la sentencia de El Mozote - en el que cuestiona el principio "no hay paz sin justicia" y afirma la necesidad de realizar un juicio de ponderación entre los intereses de la paz y los intereses de la justicia para aquellas situaciones de lesa humanidad ocurridas en conflictos armados internos ${ }^{98}{ }_{-}$, resulta contradictorio con la jurisprudencia consolidada de la propia Corte IDH, el ER, y el tratamiento que el derecho internacional ha dispensado al fenómeno de la lesa humanidad desde la aprobación por la Asamblea General de las Naciones Unidas de los Ilamados principios de Nüremberg en los años que siguieron a la Segunda Guerra Mundial ${ }^{99}$. Se trata, en nuestra opinión, de un intento de plantar una semilla revisionista frente al principio "no hay paz sin justicia", que tras décadas de cuidadosa construcción basada en la propia experiencia de la comunidad internacional, se encuentra hoy en día consolidado en el Derecho internacional.

\section{El impacto del examen preliminar de la Fiscalía de la CPI sobre la situación en Colombia en las negociaciones de paz entre el Gobierno y las FARC}

Con la creación de la CPI en 1998, la Comunidad Internacional se dotó de un órgano judicial internacional, dirigido a garantizar la investigación y enjuiciamiento de quienes por su comportamiento se han convertido en "enemigos de la humanidad", cuando no son efectivamente investigados y procesados a nivel nacional. Tanto la necesidad de una institución como la CPI como su importancia actual son incuestionables, si consideramos que en solo diez años de funcionamiento efectivo ha recibido más de 10.000 comunicaciones, ha realizado (o está realizando) exámenes preliminares con respecto a 11 situaciones (Afganistán, Colombia, Comoros, Corea del Sur, Georgia, Guinea, Honduras, Irak, Nigeria, Palestina y Venezuela), y ha abierto investigaciones en relación con otras 8 situaciones adicionales (Costa de Marfil, Darfur (Sudán), Kenia, Libia, Mali, República Centro-Africana, República Democrática del Congo y Uganda) ${ }^{100}$.

La relevancia de la CPI no se ha visto mermada por el sistema de jurisdicción compartida entre la CPI y las jurisdicciones nacionales que se consagra en el principio de complementariedad (artículos 1, 17, 18, 19 y 20 del ER) ${ }^{101}$. Conforme a este principio, la CPI constituye una jurisdicción de última ratio que solo puede activarse y ejercitarse ante la inacción, la falta de disposición o

97 OOSTHUIZEN, G. H. "Some Preliminary Remarks on the Relationship between the Envisaged International Criminal Court and the UN Security Council". Netherlands International Law Review, Vol. 46, 1999, p. 313; ABASS, Ademola. "The Competence of the Security Council to Terminate the Jurisdiction of the International Criminal Court". Texas International Law Journal, Vol. 40, 2005, pp. 263 y ss y; OLÁSOLO, Héctor. Corte Penal Internacional: ¿ Dónde Investigar? Valencia: Tirant lo Blanch, 2003, capítulo II, sección IV.

Corte IDH. Caso Masacres de El Mozote y lugares aledaños vs. El Salvador, op.cit, voto concurrente del juez Diego García-Sayán, párrs. 20-40.

Asamblea General de las Naciones Unidas, Resolución 95 (I), de 11 de diciembre de 1946; y Resolución 488(V), de 12 de diciembre de 1950.Véase también el informe presentado en 1950 por la CDI a la Asamblea General de las Naciones Unidas. ILC Commission Report. Principles of International Law Recognized in the Charter of the Nuremberg Tribunal and in the Judgment of the Tribunal, op.cit, párrs. 95-127.

Véase a esta respecto la página web oficial de la CPI: [en línea] <http://www.icc-cpi.int/en_menus/icc/structure $\% 20$ of $\% 20$ the $\% 20$ court/office $\% 20$ of $\% 20$ the $\% 20$ prosecutor/comm $\% 20$ and $\% 20$ ref/Pages/communications $\% 20$ and\%20ref> [consulta: 27 de enero de 2014].

OLÁSOLO, Héctor. "De los Riesgos y las Precauciones necesarias en la Aplicación del Principio de Complementariedad por la Corte Penal Internacional: El Estudio de la Determinación de las Penas como Objeto de Análisis de Admisibilidad". En: OLÁSOLO, Héctor. Ensayos de Derecho Penal y Procesal Internacional... op. cit, p. 128. 
la falta de capacidad de las jurisdicciones nacionales ${ }^{102}$. De ahí que pueda afirmarse la primacía formal de las jurisdicciones nacionales sobre la CPI, a los efectos de promover la persecución penal a nivel nacional de los delitos de la competencia de la $\mathrm{CPI}^{103}$. Ahora bien, el principio de complementariedad incluye un segundo aspecto consistente en la primacía material de CPI, puesto que es esta la que tiene la última palabra sobre si -a la luz de las actuaciones de las jurisdicciones nacionales- una situación es o no admisible ante la CPI. La primacía material de la CPI se dirige, por tanto, a poner fin a las situaciones de impunidad a nivel nacional de quienes se han convertido en "enemigos de la humanidad"104.

En su segundo informe sobre el examen preliminar en Colombia (cuyas conclusiones han sido recientemente refrendadas en su informe general sobre exámenes preliminares de noviembre de $2013^{105}$ ), la Fiscalía de la CPI entra en un análisis sustantivo de las actuaciones nacionales contra miembros de los distintos actores armados en el conflicto, por su responsabilidad penal en la violencia sistemática y generalizada ejercida contra la población civil desde el 1 de noviembre

En el artículo 17(1)(a) a (c) del ER, se establece que la CPI no podrá ejercer su jurisdicción por problemas de admisibilidad porque la situación de que se trate: (i) esté siendo realmente investigado o enjuiciado por un Estado que tiene competencia sobre el mismo, (ii) haya sido realmente investigado por un Estado que tiene competencia sobre el mismo y tal Estado ha decidido no enjuiciar a la persona de que se trate; o (iii) la persona de que se trata ya ha sido realmente enjuiciada por la conducta a la que se refiere la denuncia y un proceso ante la CPI violaría el principio non bis in idem. En estos supuestos, solo si se puede verificar la existencia de un problema de falta de disposición o de falta de capacidad de las jurisdicciones nacionales de los Estados afectados, cabrá declarar la situación admisible y proceder a la apertura de la investigación. Por su parte, según el artículo 17(2) del ER, nos encontramos ante un supuesto de falta de disposición de las jurisdicciones nacionales aún en el caso de que estén o hayan investigado y/o enjuiciado, cuando, a la luz de los principios de un proceso con todas las garantías reconocidas por el derecho internacional, se puede afirmar que las actuaciones nacionales: (a) se llevan a cabo con el propósito de sustraer al acusado de su responsabilidad penal por crímenes de la competencia de la Corte; (b) sufren una demora injustificada que es incompatible con la intención de hacer comparecer a la persona de que se trate ante la justicia; o (c) no son sustanciadas de manera independiente o imparcial, y además no resultan compatibles con la intención de hacer comparecer a la persona de que se trate ante la justicia. Lógicamente, en los casos del artículo 17 (1) (c) del ER, en los que las jurisdicciones nacionales han dictado sentencia firme, no cabe ya hablar de una demora injustificada en el desarrollo de unas actuaciones nacionales que ya han concluido. Por eso, en estos casos, el artículo 20 (3) del ER se refiere únicamente a que las actuaciones nacionales se hayan llevado a cabo con el propósito de sustraer al acusado de su responsabilidad penal por crímenes de la competencia de la Corte; o (b) no hayan sido sustanciadas de manera independiente o imparcial, ni sean compatibles con la intención de hacer comparecer a la persona de que se trate ante la justicia. En opinión del autor, este mismo tratamiento se debería haber dado a los supuestos del artículo 17(1) (b) del ER, que se caracterizan porque las autoridades nacionales han concluido su investigación y han decidido no ejercitar la acción penal. De otra manera, una vez que se toma la decisión de no incoar la acción penal, las actuaciones nacionales adolecerán necesariamente de una "demora injustificada," puesto que dicha decisión provocará el archivo de las actuaciones. Finalmente, el artículo 17 (3) del ER define los supuestos de falta de capacidad como aquellos en los que las jurisdicciones nacionales afectadas, debido "al colapso total o sustancial de su administración de justicia o al hecho de carecer de la misma", no pueden hacer comparecer al acusado, no disponen de las pruebas o de los testimonios necesarios, o no se encuentran en condiciones de llevar a cabo el juicio oral. Se trata, en definitiva, de supuestos excepcionales que pueden tener lugar, por ejemplo, en un contexto de ausencia de un gobierno central, de una guerra civil o de un desastre natural que provoque un colapso total o sustancial en la administración de justicia. Véase a este respecto: WILLIAMS, Sharon A. "Article 17. Issues of Admissibility". En: TRIFFTERER, Otto. (Coord.) Commentary on the Rome Statute of the International Criminal Court: Observers, Notes, Article by Article. 2a edición. Beck/Hart, 2008, pp. 383-394 y p. 394; HOLMES, John. "The Principle of Complementarity". En LEE, R.S. (Coord.) The International Criminal Court. The Making of the Rome Statute. La Haya-Londres-Boston: Kluwer International Law, 1999, pp. 41-78, pp. 54-55 y; OLÁSOLO, Héctor. Corte Penal Internacional: ¿Dónde Investigar? ... op.cit, pp. 219-221.

OLÁSOLO, Héctor. "Admisibilidad de Situaciones y Casos Objeto de Procesos de Justicia de Transición ante la Corte Penal Internacional". En: OLÁSOLO, Héctor. Ensayos de Derecho Penal y Procesal Internacional ... op.cit, pp. 60-61. 
de $2002^{106}$.

En relación con las actuaciones frente a miembros de las FARC y el ELN, la Fiscalía de la CPI hace notar que las actuaciones nacionales a través de la jurisdicción ordinaria se han extendido a los dirigentes más importantes de estos dos grupos (incluyendo 8 miembros del actual Secretariado de las FARC y 4 miembros del Comando Central del ELN ${ }^{107}$ ). Además, la Fiscalía no encuentra indicios para dudar del carácter genuino de estas actuaciones, si bien subraya la necesidad de que se ejecuten las sentencias dictadas en ausencia ${ }^{108}$.

Con respecto a los miembros de los grupos paramilitares, la Fiscalía de la CPI destaca las actuaciones desarrolladas conforme a la Ley No. 975 de Justicia y Paz y afirma que, si bien el proceso ha ido más despacio de lo esperado, esto no supone necesariamente una falta de disposición de las autoridades nacionales debido a la complejidad de los $\operatorname{casos}^{109}$. Según la Fiscalía, el principal problema existente es la ausencia de homogeneidad en la priorización de los casos, por lo que considera positiva la Directiva 0001 dictada por la Fiscalía colombiana a finales de 2012, que pone el énfasis en la necesidad de priorizar los casos frente a los máximos responsables ${ }^{110}$.

La Fiscalía de la CPI observa que de los 57 dirigentes paramilitares de mayor rango, 46 siguen vivos, y de entre estos últimos, 30 han sido condenados en relación con delitos de la competencia de la $\mathrm{CPI}$, mientras que otros 13 se encuentran actualmente imputados por este tipo de delitos ${ }^{111}$. La Fiscalía enfatiza también que el proceso de justicia y paz ha mostrado los nexos entre grupos paramilitares y miembros del Senado y de la Cámara de Representantes, habiendo sido condenados unos 50 congresistas y un pequeño grupo de altos miembros de las administraciones públicas ${ }^{112}$. Ante esta situación, la Fiscalía recalca que continúa valorando si la priorización de los casos corresponde con el criterio de los máximos responsables recogido en la Directiva 0001 y, en particular, si se da preferencia a los casos contra quienes contribuyeron

106 El primer informe de la Fiscalía CPI sobre el examen preliminar en Colombia, presenta un análisis cuantitativo de las actuaciones desarrolladas a nivel nacional contra los máximos responsables de los diferentes actores armados involucrados en la comisión de delitos de lesa humanidad, al tiempo que subraya la reducción del poder de los grupos paramilitares en los últimos años, a través del proceso de desmovilización auspiciado por la Ley de Justicia y Paz (si bien observa que un cierto número de desmovilizados ha retomado las armas reconfigurando unidades de menor tamaño y con un alto grado de autonomía, conocidas como Bandas Criminales). Véase, Fiscalía de la CPI. Report on the Preliminary Examination Activities, de 13 de diciembre de 2011, op. cit., párrs. 63-64 y 74-80. Este análisis cuantitativo resulta problemático, porque es la detallada contextualización de los distintos grupos armados al margen de la ley, y la investigación de los vínculos que los mismos puedan tener con las diferentes administraciones públicas, lo que realmente nos va a permitir determinar si las actuaciones judiciales nacionales van dirigidas a sacar a la luz la forma de organización, modus operandi y apoyo externo que permitió a los grupos paramilitares ejercitar a principios de los años 2000 un intenso control sobre una buena parte del territorio de Colombia (destacados comandantes paramilitares como Salvatore Mancuso del Bloque Norte de las Autodefensas Unidas de Córdoba y Urabá e Iván Roberto Duque, alias "Ernesto Báez" del Bloque Central Bolívar, han declarado que las autodefensas terminaron por conformar un "Estado de facto", ejerciendo el gobierno, cobrando impuestos, y decidiendo conflictos). Véanse sus declaraciones en: Tribunal Superior de Justicia de Bogotá. Sala de Conocimiento de Justicia y Paz. Decisión de control de legalidad en el caso contra Gian Carlos Gutiérrez Suárez, alias El Tuerto (Bloque Calima), caso (radicado) No. 110016000253200880786, del 30 de septiembre de 2010, párrs. 120 y 122. Véase también, OLÁSOLO, H. Principio de Complementariedad... op. cit., pp. 1 y ss.

La Fiscalía de la CPI también se refiere expresamente a los procesos desarrollados frente a 218 miembros de las FARC. Véase, Fiscalía de la CPI. Situación en Colombia, Reporte Intermedio, op. cit., párr. 12.

Ibídem, párrs.12, 160 y 161.

Ibídem, párrs. 13 y 162-167.

Ibídem, párr. 14 y 197-200.

Ibídem, párrs. 13, 168 y 169.

Ibídem, párrs. 15 y 174-179. 
a la creación, consolidación y expansión de los grupos paramilitares ${ }^{113}$.

Frente a las alegaciones presentadas contra las fuerzas y cuerpos de seguridad del Estado, la Fiscalía de la CPI observa que un buen número de miembros de las mismas han sido objeto de actuaciones penales y disciplinarias (217 condenas hasta la fecha), incluyendo 52 condenas por casos de falsos positivos (1 coronel, 8 mayores, 16 capitanes y 24 tenientes), a lo que hay que añadir los 1.699 casos que están siendo investigados en este momento por la Fiscalía colombiana $^{114}$. A la luz de estas circunstancias, la Fiscalía de la CPI concluye que continúa examinado si dichas actuaciones se dan exclusivamente contra los autores materiales, o se dirigen a dilucidar la responsabilidad penal de los comandantes ${ }^{115}$.

La Fiscalía de la CPI ve también con particular preocupación las escasas actuaciones nacionales desarrolladas hasta la fecha por delitos de desplazamiento forzado, violación y otros abusos sexuales (solo cuatro personas, incluyendo a dos miembros de grupos paramilitares, han sido condenados por delitos sexuales), lo que en su opinión contrasta con el alto número de víctimas que han sido identificadas ${ }^{116}$.

Finalmente, la Fiscalía de la CPI analiza el Ilamado "Marco Jurídico para la Paz", aprobado a través del acto legislativo 01 de 2012, por el que se introducen dos artículos transitorios (artículos 66 y 67) a la Constitución Política de Colombia, en los que -en su opinión-, se recoge toda una "estrategia de justicia transicional", consistente en la creación de una Comisión de la Verdad y de un régimen de reparaciones en vía administrativa, el establecimiento de criterios de selección y priorización de casos, la previsión de penas alternativas y regímenes especiales de suspensión y ejecución de penas en los casos seleccionados, y el establecimiento de un sistema de sanciones extrajudiciales para los casos no seleccionados ${ }^{117}$.

Entre las medidas adoptadas, para la Fiscalía serían particularmente preocupantes las relativas a la selección y priorización de casos. En particular, cabe destacar la atribución del Congreso de la República para centrar por vía legislativa los esfuerzos de investigación y enjuiciamiento penal en los máximos responsables de aquellos delitos constitutivos de genocidio, lesa humanidad y crímenes de guerra, que sean cometidos de manera sistemática, tengan la gravedad suficiente, y supongan casos representativos de la violencia acaecida en Colombia (selección de casos) ${ }^{118}$. Esta facultad viene acompañada de la atribución del propio Congreso de la República para renunciar por vía legislativa al ejercicio de la acción penal de todos los casos no seleccionados ${ }^{119}$. Además, se reconoce a la Fiscalía General de la Nación la competencia para establecer criterios de priorización que considere oportunos en relación con aquellos casos que han sido seleccionados por el Congreso de la República ${ }^{120}$. Frente a estas medidas, la Fiscalía de la CPI hace hincapié en el riesgo de impunidad frente a superiores medios y autores materiales a los que puede llevar la articulación práctica de los mencionados criterios de selección y priorización ${ }^{121}$.

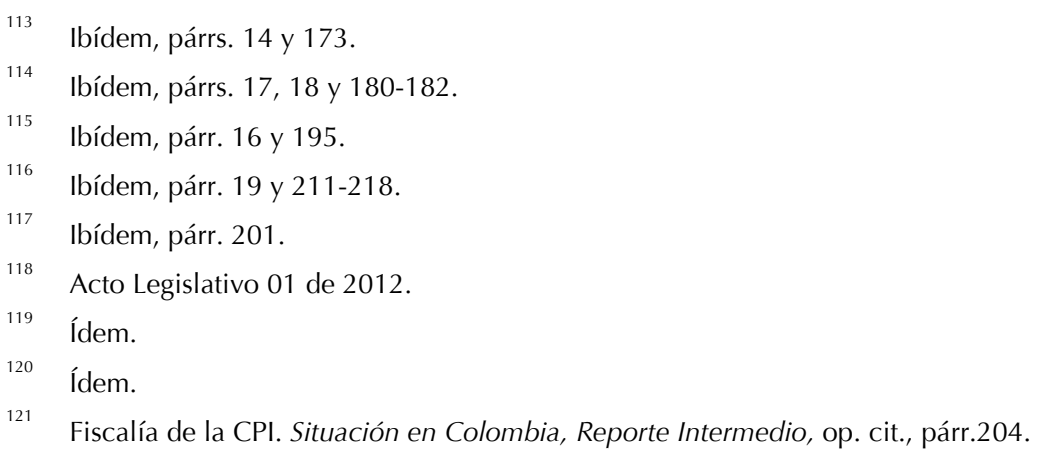


La Fiscalía de la CPI muestra también su preocupación por la aplicación de penas alternativas en los casos seleccionados, así como por los regímenes de suspensión y ejecución especial de las penas. Destaca a este respecto la atribución al Congreso de la República de determinar los criterios y condiciones en los que procedería la suspensión de la ejecución de la pena en los casos seleccionados (es decir, aquellos dirigidos contra los máximos responsables de delitos de genocidio, lesa humanidad y crímenes de guerra, cometidos de manera sistemática, con la gravedad suficiente, y constitutivos de casos representativos de la violencia acaecida en Colombia) ${ }^{122}$. Junto a esta facultad, se atribuye también al Congreso de la República la potestad para establecer los supuestos en los que proceda la aplicación de penas alternativas o de modalidades especiales de ejecución y cumplimiento de la pena (como sería, por ejemplo, la pena alternativa de 5 a 8 años actualmente aplicable en el marco de la Ley No. 975 de Justicia y Paz, o el cumplimiento de la pena en el domicilio privado del condenado) ${ }^{123}$.

A la luz de lo anterior, la Fiscalía de la CPI concluye que "[e]xiste la posibilidad de que el Marco Jurídico para la Paz tenga repercusiones en el desarrollo de las actuaciones relativas a crímenes de la competencia de la CPI y en la evaluación de la admisibilidad de casos ante la misma; por lo tanto, su aplicación guarda una relación directa con el examen preliminar de la situación en Colombia"124.

Pero, sin duda, lo más relevante del informe de la Fiscalía es la inequívoca afirmación de que, fruto de las anteriores consideraciones, la Fiscalía de la CPI considera necesario mantener su examen preliminar sobre Colombia, con particular atención al desarrollo de las actuaciones nacionales sobre (i) los delitos de desplazamiento forzado, violación y otros abusos sexuales, (ii) el fenómeno de los falsos positivos, (iii) la continuación de las actuaciones penales contra comandantes paramilitares, y los aspectos jurisdiccionales relacionados con el surgimiento de los "nuevos grupos armados ilegales", y (iv) la regulación estatutaria del Marco Jurídico para la Paz (de manera que no se afecte la investigación, enjuiciamiento y cumplimiento de penas a nivel nacional de los máximos responsables de los delitos de lesa humanidad cometidos por las FARC, el ELN, los grupos paramilitares y las fuerzas armadas y de policía de Colombia) ${ }^{125}$.

De esta manera, la Fiscalía de la CPI nos recuerda que con la firma y ratificación del Estatuto de la CPI, Colombia ha reafirmado los principios informadores de la regulación internacional del fenómeno de la lesa humanidad, se ha comprometido expresamente a la persecución penal de violencia sistemática y a gran escala ocurrida en su territorio contra la población civil, y ha aceptado la intervención directa de la CPI en caso de no actuar, o de hacerlo sin una auténtica disposición de traer a los máximos responsables ante la justicia o adoleciendo de una auténtica falta de capacidad al respecto.

El reconocimiento de esta realidad, y la necesidad de buscar fórmulas que avancen conjuntamente los intereses de la justicia y la paz (siguiendo el principio "no hay paz sin justicia" imperante actualmente en la legalidad internacional), se presenta -en nuestra opinión- como un reto importante en las actuales negociaciones de paz. Los representantes del gobierno colombiano y de las FARC no pueden sino afrontar este reto ante la atenta mirada de los organismos internacionales de supervisión (CPI y $\mathrm{CIDH})$, cuyo mandato es asegurar que cualquier acuerdo adoptado por los actores del conflicto colombiano respete el interés que en el mismo tiene la comunidad internacional, y se lleve a cabo dentro de los parámetros establecidos por aquella

\footnotetext{
122 Acto Legislativo 01 de 2012.

123 Ídem.

124 Fiscalía de la CPI. Situación en Colombia, Reporte Intermedio, op. cit, párr. 203.

125 íbídem, párr. 22.
} 
en el orden jurídico internacional.

Es por ello que, como primera medida para evitar que el proceso de paz se pueda truncar en el medio plazo, los negociadores han de asegurarse que se ajustan desde un principio al derecho internacional. De lo contrario, se exponen a que sus acuerdos se vean posteriormente anulados por los organismos internacionales de supervisión. Ello exige que, tal y como pone de manifiesto el informe de noviembre de 2012 de la Fiscalía de la CPI, se deba dejar desde un primer momento a un lado la retórica de las exenciones de responsabilidad penal, ejercicios del principio de oportunidad que generan brechas de impunidad, suspensiones de ejecución de las penas o concesiones de indultos a los máximos responsables de los delitos de lesa humanidad cometidos por los distintos actores armados en Colombia. Esto, para que -conforme a lo requerido por el derecho internacional general y las obligaciones voluntariamente contraídas por Colombia-, los negociadores no promuevan (como con frecuencia ha sucedido en el pasado) la postergación de los intereses de la justicia, con el sofisma de pretender así avanzar en los intereses de la paz.

\section{Conclusión: el impacto del caso colombiano en futuras negociaciones de paz en América Latina}

Con la aprobación de los Estatutos del TPIY (1993), el TPIR (1994) y la CPI (1998) ${ }^{126}$, la regulación del fenómeno de lesa humanidad ha adquirido el valor de norma de ius cogens, de manera que los Estados que forman parte de la comunidad internacional (1) han aceptado que en situaciones de violencia sistemática o generalizada contra la población civil, los valores paz y justicia deben ir necesariamente de la mano (sin que el segundo pueda quedar desplazado por el primero), (2) han subrayado la necesidad moral y legal de combatir su impunidad, y (3) han afirmado que la justicia penal es una condición necesaria para obtener una paz sostenible en el tiempo, para alcanzar la reconciliación y para promover la democracia. Como hemos visto, esta situación se ha visto reflejada en la jurisprudencia constante de la Corte IDH.

En este contexto, la llamada justicia transicional encuentra importantes limitaciones en su ámbito de aplicación al fenómeno de la lesa humanidad. Esto se refleja, en particular, en la proscripción de medidas dirigidas a eximir de responsabilidad, aplicar el principio de oportunidad generando brechas de impunidad, suspender la ejecución de penas y conceder indultos. Estas medidas constituyen en la actualidad graves violaciones de normas fundamentales del derecho internacional, al menos en lo que toca a los máximos responsables de los delitos de lesa humanidad.

El examen preliminar de la Fiscalía de la CPI sobre Colombia tiene un impacto muy significativo sobre las negociaciones de paz entre el gobierno colombiano y las FARC. Desde una perspectiva sustantiva, exige que dichas negociaciones partan desde el reconocimiento de la necesidad de buscar fórmulas que avancen conjuntamente los valores de la justicia y la paz, siguiendo el principio "no hay paz sin justicia" que informa hoy en día el ordenamiento jurídico internacional. Desde una perspectiva jurisdiccional, supone que el diálogo entre el gobierno y las FARC se esté produciendo ante la atenta mirada de los organismos internacionales de supervisión (CPI y $\mathrm{CIDH}$ ), cuyo mandato es garantizar que cualquier acuerdo al que lleguen los negociadores respete el interés de la comunidad internacional, en que los máximos responsables de los delitos de lesa humanidad cometidos en Colombia no permanezcan en la impunidad. La publicación del segundo informe de la Fiscalía de la CPI sobre Colombia el 12 de noviembre de 2012, cuando todavía no había pasado un mes desde el inicio oficial del proceso de negociación el 16 de octubre de 2012 y días antes de su continuación en La Habana, no puede entenderse sino

126 Véase a este respecto, entre otros, BASSIOUNI, M. Cherif. Accountability for Violations... op. cit., pp. 3 y ss; y BENAVIDES, Farid. Justicia en Épocas... op. cit., pp. 24-25. 
Héctor Olásolo Alonso / Los exámenes preliminares de la Corte Penal Internacional en América Latina: el caso colombiano y su impacto...

como un recordatorio a las partes del contexto sustantivo y jurisdiccional en el que desarrollan sus negociaciones.

Sin embargo, conviene subrayar que la importancia de las actuaciones de la Fiscalía de la CPI con respecto a Colombia va mucho más allá, puesto que a través de las mismas se está definiendo con precisión aquellas medidas proscritas por el derecho internacional, que no pueden ser objeto de negociación por actores implicados en delitos de lesa humanidad. De esta manera, una vez precisados los límites de la justicia transicional con respecto al fenómeno de la lesa humanidad, estos serán aplicados no solo para evaluar futuros procesos de paz en América Latina, sino para analizar aquellas negociaciones que se han venido realizando en la región desde la creación de la $\mathrm{CPI}$.

Este sería, en particular, el caso de las negociaciones celebradas en el segundo semestre de 2009 en Honduras, entre el antiguo gobierno de Manuel Zelaya y el gobierno surgido del golpe de Estado de Roberto Micheletti, con la mediación de la Organización de Estados Americanos y el Presidente de Costa Rica. Las mismas concluyeron en el Ilamado "Acuerdo de Tegucigalpa", que contiene tres elementos principales que deberán ser objeto de análisis por la Fiscalía de la CPI en el marco de su examen preliminar: (i) la formación de un gobierno único mediante elecciones (que Ilevaron a Porfirio Lobo a la presidencia el 27 de enero de 2010); (ii) la aprobación de una amnistía para todos los intervinientes en los acontecimientos del 28 de junio de 2009, excepto para quienes fueran responsables de delitos de lesa humanidad y graves violaciones de derechos humanos (que se concretó en el decreto presidencial de 2 de febrero de 2010), y (iii) la creación de una Comisión de la Verdad y Reconciliación (establecida en abril de 2010, y cuyo informe se emitió en julio de 2011).

En consecuencia, podemos afirmar que los ejemplos de Colombia, Honduras y Venezuela, nos muestran como la actividad desarrollada por la Fiscalía de la CPI a través de sus exámenes preliminares tiene un impacto en América Latina mucho más importante de lo que pudiera parecer en un primer análisis. 